\title{
Gizli Tehdit: Et Yiyen Zoonoz Bakteriler
}

\section{Hidden Threat: Flesh-Eating Zoonotic Bacteria}

\section{Aliye SAĞKAN ÖZTÜRK ${ }^{1}$, Serkan İrfan KÖSE ${ }^{2}$}

${ }^{1}$ Doç. Dr. Hatay Mustafa Kemal Üniversitesi, Veteriner Fakültesi, İç Hastalıkları Anabilim Dalı, HATAY
${ }^{2}$ Dr. Öğr. Üyesi. Hatay Mustafa Kemal Üniversitesi, Veteriner Fakültesi, İç Hastalıkları Anabilim Dalı, HATAY

\section{Öz}

Nekrotizan fasiit, hem insanlarda hem de hayvanlarda yumuşak dokuların hızla ölümüne sebep olabilen ve bazen daha derin dokulara kadar ilerleyebilen bakteriyel bir deri hastalığıdır. Bu bakterilerden bazıları yalnızca insanlarda enfeksiyona neden olur iken bir kısım bakteride hayvanlarla ya da su canlıları ile bütünlügü bozulmuş deri ile temas halinde ya da ısırık/çizikler vasıtası ile vücuda alınıp nekrotizan fasiite sebep olabilen zoonoz etkenlerdir. Nekrotizan fasiite neden olan zoonoz karakterli bakteriler hakkında pek çok vaka takdimi yapılmıştır. Enfeksiyonun tanımlanmasında hastanın mutlaka detaylı hikayesi dinlenmeli herhangi bir temas ile karşı karşıya kalındığında yara bakımının yapılmasına ek olarak sistemik tedavi girişimlerinde de bulunulmalıdır. Aksi takdirde hastanın genel sağlık durumuna göre uzuvlarda kayıplar, septisemi ve çoklu organ yetmezliklerine kadar ilerleyebilen ciddi bir hastalık tablosu meydana gelmekte ve böyle vakaların çoğu da ölüm ile sonuçlanmaktadır. Bu derlemenin amacı, hayvanlardan insanlara temas ile bulaşabilen ve nekrotizan fasiite sebep olan etkenler hakkında bilgi vermek ve hem veteriner hekimleri hem de hayvan sahipleri/severlerinin farkındalıklarını artırmaktır.

Anahtar Kelimeler: Bakteri, nekrotizan fasiit, zoonoz

\section{Abstract}

In both human and animals, necrotizing fasciitis is a bacterial integumentary disease causing fulminant soft tissue death and tending to spread into the depth tissue. While some of these bacteria cause infections only in human, a part of these bacteria infecting to human with contact to erupted skin or bites and scratch by animals or aquatic animals are the zoonotic agents of Necrotizing fasciitis. Many case studies on zoonotic bacteria causing necrotizing fasciitis have been reported. In the diagnosis of infection, the patient's detailed history should be taken and the patient should be treated with systemic treatment interventions, in addition to the wound care in exposing of any contact. Otherwise, according to the general health status of the patient, severe diseases progressing to loss of limbs, septicemia, and multiple organ deficiencies occur and also the most of these cases result in death. The aim of this review is to provide information about causative agents of necrotizing fasciitis that can be transmitted by contact from animals to humans, and to raise awareness of both veterinarians and animal owners or lovers.

Key Words: Bacteria, necrotizing fasciitis, zoonotic

\section{GİRIŞ}

Nekrotizan fasiit, vücudun yumuşak dokusunu öldüren ve hızla yayılan ciddi bakteriyel deri enfeksiyonudur. Erken belirtiler ateş, şiddetli ağrı, şişlik ve yara bölgesinin kızarmasını içerir $(1,2)$. Nekrotizan fasiit çok kısa bir süre içinde ölümcül olabilir. Doğru tanı, hızlı antibiyotik tedavisi ve cerrahi müdahale enfeksiyonu durdurmak için önemlidir (3). Her ne kadar medya yaygin olarak "et yiyen bir enfeksiyon" olarak adlandirsa da, insanlarda birden fazla bakteri türü bu nadir hastalığa neden olabilir. Bu bakteriler A grubu Streptococcus (grup A streptococcus), Klebsiella, Clostridium, Escherichia coli, Staphylococcus aureus ve Aeromonas hydrophila'dır. Halk sağlığı uzmanları, grup A Streptococcus'un nekrotizan fasiitin en yaygın etkeni olduğunu düşünmektedir $(4,5)$. İnsanlarda, en yaygın A grubu streptokoklardan kaynaklanır (6). Metisiline dirençli Staphylococcus aureus (MRSA)'nın neden olduğu vaka raporları da bulunmaktadır (7).

Nekrotizan fasiit vakalarında, bakteriler vücuda girdiğinde hızla yayılır. Kasları, sinirleri, yağ dokuyu ve kan damarlarını çevreleyen bağ dokusunu enfekte ederler. Enfeksiyon aynı zamanda fasyanın yanındaki dokulara da zarar verir. Bazen bu bakteriler tarafından üretilen toksinler, enfekte ettikleri dokuları yok ederek ölmesine

$\begin{array}{ll}\text { İletişim: } & \begin{array}{l}\text { Dr. Öğr. Üyesi Serkan İrfan KÖSE, Hatay Mustafa Kemal } \\ \text { Üniversitesi, Veteriner Fakültesi, Klinik Bilimler Bölümü } \\ \text { İç Hastalıkları Anabilim Dalı, Alahan-Antakya / Hatay }\end{array} \\ \text { DOI: } & \mathbf{1 0 . 1 7 5 1 7 / k s u t f d . 4 3 8 3 4 4}\end{array}$

neden olurlar. Bunun sonucunda da hastalar uzuvlarını kaybedebilir veya ölebilirler (2). ABD'de nekrotizan fasiit seyrek olmakla birlikte yılda yaklaşı 500-1500 vakaya rastlanmakta, hastalığın şiddeti, hızlı ilerlemesi, yüksek ölüm oranı ve "et yiyen hastalıklar" olarak adlandırılan kollektif tanımlamalardan dolayı büyük ilgi görmektedir (8).

İnsanlarda direk nekrotizan fasiite sebep olan etkenlerin yanı sıra, evcil hayvanlar ve bazı su canlılarından insanlara bulaşan ve nekrotize fasiite sebep olan zoonoz karakterli etkenlerde mevcuttur. $\mathrm{Bu}$ etkenler genellikle yaşli, diyabet gibi kronik hastalığ olanlarda, alkol bağımlılarında ve İnsan Bağışıklık Yetmezlik Virüsü-HIV gibi immunosupresif tabloya yol açan hastalıktan muzdarip bireylerde yaygın olarak görülmektedir $(4,9)$. Bunlar aşağıda başlıklar halinde detayları ile açıklanmıştır.

\section{Capnocytophaga canimorsus}

Capnocytophaga canimorsus, köpeklerin ve kedilerin ağız boşluğunda normal florada bulunan komensal bir bakteridir (10). Köpeklerde ilk olarak Van Dam ve ark. PCR ile test ettikleri köpeklerin \%74'ünde

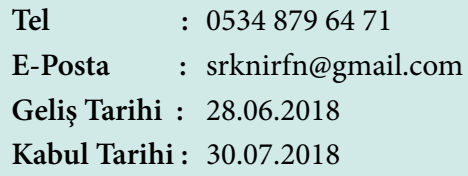


etkeni füziform hareket yeteneğine sahip kapnofilik, fakültatif anaerobik, basil olarak tanımlamışlardır (11). Köpeklerde enfeksiyona neden olmazken, insanlarda nadir ancak şiddetli enfeksiyonlara neden olabilmektedir (12).

Enfeksiyonların yarısında peteşi, purpura, selülit, kangren, eskariasyon ve ürtikeryal lezyonları içeren deri bulguları vardır (13). Ayrıca 1sırık bölgesinde nekrotizan kabuk ile karakterizedir (14). Jordan ve ark, sokakta yaşayan evsiz ve 59 yaşında alkolik, sağ total diz artroplastisi ve tip 2 diyabet geçmişi olan bir erkek hastada, bir gündür kötüleşen sağ diz ağrısı, deride döküntü, subjektif ateş ve generalize ağrı belirlemişlerdir (15). Uyluk bölgesinde çoklu, dağınık peteşiler olan hastanın üç hafta önce kendisine ait ve aşılanmış köpeği ile oynarken sağ elinden 1sırıldığ ve yaraları sabun ve suyla yıkadığ kutanöz lezyonların ayırıcı tanısında C. canimorsus'un da düşünülmesi gerektiği sonucuna varılarak etkenin ürtikeryal ekzantem ile ilişkili olup olmadığını belirlemek için daha fazla vaka biriktirilmesi gerektiği sonucuna varild.

Dermatolojik bulguların dışında C. canimorsus özellikle immun sistemi baskılanmış, splenektomi geçirenler, alkolikler ve kronik hastalık öyküsü olanlarda bakteriyemi ve septisemi ile seyretmekte ve mortalite oranı \% 25'lere çıkarak önemi artmaktadır $(14,16)$. Ancak enfeksiyonun bakteriyemi evresine geçebilmesi için konakta bir takım yapıcı faktörlerin bulunması gerekmektedir. Özellikle sitotoksik veya biyolojik ilaç kullananlar, HIV'li hastalar, hematolojik malignitesi olanlar ve buna bağlı immun yetmezlikli ve sepsise duyarlı bireylerde köpek veya kedi ısırı̆̆ı veya çizikleri sonrasında gelişebilir. Etken bu hasta grubunda sepsis / septik şok geliştirmeye yatkındır ve vakalar ölümle neticelenebilmektedir $(17,18)$. Bununla birlikte, son zamanlardaki retrospektif çalışmalarda, enfekte hastaların yaklaşık \% 40’ının bu tür tıbbi öyküleri bulunmayan sağlıklı bireyler oldukları bildirilmiştir $(19,20)$. Klinik olarak bildirilen ve bu etken ile enfekte olan vakaların \%41'i sepsis ve / veya septik şok ile sonuçlanmıştır (21). C canimorsus'un isırık veya yalamanın dışında aerosol yolla da bulaşabileceği ifade edilmektedir (22).

C. canimorsus standart laboratuvar kültürlerinde özel besi yerlerine ihtiyaç duyması ve yavaş üremesi nedeni ile tespitte gözden kaçabilir. Bu sebeple PCR bu tür enfeksiyon etkenleri ve türlerini tanımlamak için kullanışlı ve hızlı bir araç gibi görünmektedir $(23,24)$. Canimorsus enfeksiyonu konağın bağışıklık sisteminden kolayca kaçma yeteneği nedeniyle sepsise yol açar $(24,25)$. Bu nedenle splenektomi veya alkolizm ile azalmış makrofaj fonksiyonu ve bozulmuş bağışıklık, C. canimorsus enfeksiyonlarını şiddetlendirebilir $(19,20$, $26,27)$.

\section{Pasteurella multocida}

Pasteurella multocida, köpekler ve kedilerinde dahil olduğu evcil hayvanların normal florasında bulunan, Pasteurellaceae ailesine ait Gram-negatif, hareketsiz, aerobik kokobasildir. Penisiline duyarlıdır. Genellikle evcil hayvanlar tarafından oluşturulan isırıklar ya da çizikler sonucu insanlarda zoonotik enfeksiyon KSU Medical Journal 2019;14(1) 42-48 oluştururlar. İnsanlarda selülit, bakteriyemi, pnömoni, yara apsesi ve septik artrit gibi birçok hastalığın ortaya çıkmasına sebep olabilmektedir (28). Aynı zamanda ölümcül bir yumuşak doku enfeksiyonu olan nekrotizan fasiite de nadiren sebep olabilmektedir (29). Chang ve ark. (30) kronik böbrek yetmezliği, gut artriti ve iyatrojenik Cushing sendromu öyküsü olan 58 yaşında erkek hastada ölümcül bir P. multocida bakteriyemi ve nekrotizan fasiit olgusuna rastlamış ve P. multocida fasiitinin tedavisi hakkında bilgi vermişlerdir. Hayvan sahibinden alınan anemnezde köpek ile herhangi bir 1sırılma hikayesi olmayıp köpek tarafından açık yarası ve gut artrit bölgesinin yalandığı ifade edilmiştir. Köpeğinden alınan salya örneğinin kültüründe ise $P$. multocida ve Pseudomonas aeruginosa pozitif olarak belirlenmiştir (30). Bu vakadan önce P. multocida'nın sebep olduğu nekrotizan fasiit Hamamoto ve ark.ları tarafindan da bildirilmiștir (29). Bildirdikleri vakada ise hayvan teması olmaksızın kronik karaciğer hasarı öyküsü bulunmaktadır. Sonuç olarak, P. multocida' nın, özellikle açı yaralı ve köpeklerle yakın temasta bulunan ancak yalnızca ısırılma durumlarında dikkate alınmaması gereken, riskli konakçılarda nekrotizan fasiite neden olan potansiyel bir patojen olarak kabul edilmesi gerektiği ortaya konulmuştur.

\section{Streptokok Türleri}

Streptokoklar Streptococcaceae familyasında yer alan gram pozitif koklardır (31). Genellikle zincir şeklinde ve özellikle de sıvı ortamlarda bulunurlar. Streptococcus cinsinin birçok üyesi, insanlar ve hayvanlar için patojendir. Yine bazı türlerin de zoonotik olduğu kanıtlanmıştır. Streptokokların zoonotik türlerini ve insanlardaki önemlerini tanımlamak zordur. Bunlardan bazıları S. equi subsp. zooepidemicus (pek çok türde), S. suis (domuzlarda), S. iniae (balıklarda), S. canis (köpek ve diğer türlerde)'dir. Bunların dışında $S$. pyogenes ve $S$. agalactiae için hayvanlar taşıyıcı olmasa bile ters-zoonoz olarak etken taşınabilmektedir $(32,33)$.

S. zooepidemicus'un (S. equi subsp. zooepidemicus) neden olduğu zoonotik nekrotizan miyozit ilk defa Kittang ve ark. tarafından klinik olarak sağlıklı midillileri beslerken yakın temasta bulunan ve ardından sol uyluğunda eritem oluşumunun sonrasinda hızlı sepsis ve çoklu organ yetmezliği meydana gelen 73 yaşındaki bir çiftçide tanımlanmıştır (34). Multidisipliner bir yaklaşımın ardından hızlı klinik tanımlama, erken ve tekrarlı cerrahi, yeterli destek tedavi ile yumuşak doku nekrozu tedavi edilmiștir.

S. canis, zoonoz olmasının yanı sıra köpekler ve kedilerde fırsatçı bir patojendir. Köpeklerde, S. canis, deri ve üreme organlarının enfeksiyonları, mastitis, pnömoni, septisemi ve streptokokal toksik şok sendromuna (STSS) sebep olabilmektedir (35). Enfeksiyon invaziv karakterde olup akut başlangıçlı, hızlı ilerleyen, kısa süre içerisinde yüksek ölüm oranı ile seyreder. Yüksek ateş, kusma, öksürük, şok, hafif konvülsiyonlar, yoğun ağrı ve hızlı kontrolsüz kas fasikülasyonu ile karekterize olup selülit ve nekrotizan fasiitde bazı vakalarda tanımlanmıştır (36). S. canis kedilerde artrit, yara enfeksiyonları, pnömoni ve streptokok toksik şok sendromu, 3 ila 6 aylık yavrularda lenfadenit, septisemi 
ve bazen neonatal septisemiye neden olabilir (37). Streptococcus canis'in neden olduğu STSS ve nekrotizan fasiitin tanımlanması, bu organizmanın virülansının ve klinik vakaların değerlendirilebilirliğini arttırmıştır (38). Köpeklerde nekrotizan fasiite sebep olan etken insanlarda septisemi bulgularına sebep olabilmektedir (39). Bert ve Lambert-Zechovsky alt ekstremitelerinde ülseri olan 77 yaşındaki bir erkek hastada köpeğinin ülseri ile temas etmesi sonucu S. canise bağlı bir septisemi olgusunu tanımlamışlardır (40). Yine grup A Streptococcus spp bakterileri insanlarda nekrotizan fasiite sebep olmakta ve evcil hayvanların yaralamaları sonucu deri bütünlügünün bozulması etkenin vücuda girişine ve derin dokulara yayılmasına zemin hazırlamaktadır. Kedi ısırığı sonrası dördüncü gün ellerinde nekrotizan fasiit gelişen bir kadında buna örnek olarak verilebilir (41). Ayrıca bu enfeksiyonlar ekstremitelerde ampütasyona kadar ilerleyebilir ve bazı durumlarda hastaların hayatta kalma şansları düşük olabilir. Isırılma geçmişi olmaksızın köpeklerle temas halinde olan hayvan sahiplerinde de şiddetli enfeksiyonların gelişebildiği bildirilmiştir (42). Bu sebeple evcil hayvanlar tarafindan isırılma ya da çizilme vakaları daha fazla ciddiye alınmalı ve yara bakımları mutlaka yapılarak gerekli görüldüğü takdirde sistemik antibiyotiklerde kullanılmalıdır (41).

\section{Stafilokok Türleri}

Staphylococcus pseudintermedius, ilk olarak 2005 yılında tanımlanan bir koagülaz pozitif Stafilokokus'tur (43). S. pseudintermedius enfeksiyonu tanımlayan sinırlı sayıda rapor bulunurken, köpeklerde $(44,45)$, son zamanlarda, S. intermedius olarak sınıflandırılmış köpek izolatlarının pek çoğunun S. pseudintermedius olduğu ve S. pseudintermedius'un önemli bir köpek patojeni olabileceği kanısına varılmıştır $(46,47)$. Köpeklerde S. intermedius tipik olarak piyoderma ve benzeri cilt ve yumuşak doku enfeksiyonlarına neden olur, ancak diğer vücut bölgelerinde firsatçı enfeksiyonlara da neden olabilmektedir (48).

Weese ve ark. 2009 yılında 15 yaşlı bir köpekte, hızla ilerleyen ve ölümcül olan nekrotizan fasiitin etkeninin S. pseudintermedius olduğunu ortaya koyarak, yalnızca Streptococcus canis'in köpeklerde nekrotizan fasiitin ana nedeni olmayıp, stafilokokların da nekrotizan fasiit için etken olarak düşünülmesi gerektiğini ortaya koymuştur (49).

İnsanlarda S. intermedius'un sebep olduğu nekrotizan fasiit için tek bir olgu sunumu vardır. Bununla birlikte, aynı vakada metisiline dirençli Staphylococcus aureus'un da izole edilmiș olması sebebi ile etkenin önemi açık değildir (50).

\section{Su Canlılarından Kaynaklanan Nekrotizan Fasiit}

Evcil hayvanlardan bulaşan zoonoz hastalıkların yanı sıra su canlılarından da bulaşabilen nekrotizan fasiit karekterli mikroorganizmalar bulunmaktadır. Bunların en önemlilerinden biri Vibrio cinsi, Vibrionaceae familyasının gram negatif, fakültatif anaerobik çubuklarıdır. Vibrio türleri tuzlu su ortamlarında daha yaygın olmasına rağmen, tatlı su balıklarından da bazen izole edilebilen tipik olarak llık suda çoğalan ve genellikle sıcak aylarda daha bol ortaya çıkan mikroorganizmalardır (51). Klinik olarak normal görünen balıkların deri ve gastrointestinal kanallarında bulunabilen etken stresli koşullar altında balıklarda da hastalığa neden olabilirler (52). Yaygın olarak tanımlanan türler Vibrio vulnificus, Vibrio parahemolyticus ve Vibrio cholera'dır. İnsanlarda, Vibrio vulnificus enfeksiyonu en yaygin balık kaynaklı Vibrio enfeksiyonu olup, etken başlica yara veya oral yol ile az pişmiş su canlılarından alınmaktadır (53). İnsanlarda klinik belirtiler nekrotizan fasiit, ödem ve şişlik oluşumudur (54). V vulnificus, genellikle çiğ istiridyelerin yenilmesinden sonra klinik olarak etkilenmiș insanlarda (\%50-60) septisemi ve ölüme kadar gidebilen klinik tablolar şekillendirebilmektedir (55). Ayrıca karaciğer hastalığı olanlar, çiğ veya az pişmiş kabuklu su canlılarını yedikten sonra ya da kontamine su ile travmatize cildin maruziyeti sonrası Vibrio vulnificus enfeksiyonuna bağlı sekonder nekrotizan fasiit gelişmesi için yüksek risk altındadır (56).

Yine Enterobacteriaceae familyasına ait zoonotik potansiyele sahip başka bakteri türleri de vardır. $\mathrm{Bu}$ bakteriler arasında Edwardsiella, Escherichia, Salmonella ve Klebsiella spp. bulunur (57). Bu bakteriler, balık türleri veya tatlı su ile doğrudan ilişkili olan gram-negatif, fakültatif anaerobik çubukları içerir. Bunlardan sadece Edwardsiella ictaluri ve Edwardsiella tarda balıklar için birincil önemli patojenlerdir ve her ikisi de ticari gıdabalık endüstrisinde önemli kayıplara neden olmaktadır. İnsanlarda ise enfeksiyonun kaynağ 1 balıkların taşınması veya muayenesi sırasında meydana gelen açik yaralar, kesik ve sürtünmeler aracılı̆̆g ile meydana gelen kontaminasyonlardır (58). Edwardsiella tarda enfeksiyonu yayın balıklarında amfizematöz kokuşma/ putrifikiye bir hastalık olarak tanımlanır ve peteşi ile cildin ülserasyonunu ve aşırı mukus üretimini içeren nonspesifik klinik belirtilerle ortaya çıkar. İnsanlarda ise açık yara veya oral yolla E. tarda ile enfeksiyon meydana gelebilmekte ve nekrotik cilt lezyonları ve gastroenterit gelişebilmektedir $(59,60)$. Bu bakterilerin meydana getirdiği enfeksiyonlar lokal olabileceği gibi sistemik bir seyir ile ciddi menenjit vakalarına da neden olabilir (61, 62).

Edwardsiella tarda, esasında insanlarda nadir rastlanan bir patojen olup özellikle immün yetmezliği olan bir hastada ilk bildirilen miyonekroz vakası dahil olmak üzere, 11 adet bağırsak dışı E. tarda enfeksiyonu vakası sunulmuş ve vakaların bir kısmında su canlılarının avlandığı ortama maruz kalındığı bilgisi alınmıştır. Bununla birlikte vakalardan birinde septisemi olmasina rağmen diğerlerinde miyonekroza rastlandığ 1 ifade edilmektedir. Slaven E. tarda enfeksiyonu nedeniyle meydana gelen miyonekroz hakkındaki ilk vakayı tanımlamışlardır (63). Bu vakada 48 yaşında balık ve yengeç avlarken kolunu yaralayarak balık tuttuğu su ile temas etme sonucu meydana gelen myositisin etkeni E. Tarda olarak tanımlanmıştır.

\section{Diğerleri}

Köpek ısırığı ile yaygın olarak bulaşan Pasteurella multocida ve Capnocytophaga canimorsus (16) gibi etkenlerin dışında, diyabetik 38 yaşlıbirkadın hastada basit 
Tablo 1. Evcil hayvanlardan ve bazı su canlılarından insanlara bulaşan etkenler.

\begin{tabular}{|c|c|c|c|}
\hline Mikroorganizma & Taşıyıcı lokalizasyonu & Konakçı Lokalizasyonu & $\begin{array}{l}\text { Konakçıda Gelişebilecek } \\
\text { Problemler }\end{array}$ \\
\hline Capnocytophaga canimorsus & $\begin{array}{l}\text { Köpek ve kedilerin ağız } \\
\text { boşluğu }\end{array}$ & Isırık/kontak bölgesi & $\begin{array}{l}\text { Deri lezyonları } \\
\text { Peteşi, } \\
\text { Purpura, } \\
\text { Selülit, } \\
\text { Kangren, } \\
\text { Eskariasyon } \\
\text { Ürtikeryal lezyonları } \\
\text { Bakteriyemi } \\
\text { Septisemi } \\
\text { Septik şok } \\
\text { Ölüm }\end{array}$ \\
\hline Pasteurella multocida & Köpek ağız boşluğu, Salya & Isırık, yalama ya da çizik bölgesi & $\begin{array}{l}\text { Selülit, } \\
\text { Bakteriyemi, Pnömoni, } \\
\text { Yara apsesi } \\
\text { Septik artrit } \\
\text { Nekrotizan fasiit }\end{array}$ \\
\hline $\begin{array}{l}\text { Streptococcus equi subsp. } \\
\text { zooepidemicus }\end{array}$ & Tek tırnaklı hayvanlar & Isırık, yalama ya da çizik bölgesi & $\begin{array}{l}\text { Nekrotizan miyozit } \\
\text { Deri lezyonu } \\
\text { Eritem } \\
\text { Sepsis } \\
\end{array}$ \\
\hline Streptococcus canis & Köpek ağız boşluğu, Salya & Isırık/kontak bölgesi & Septisemi \\
\hline Streptococcus spp & $\begin{array}{l}\text { Köpek ve kedilerin ağız } \\
\text { boşluğu }\end{array}$ & Isırık, yalama ya da çizik bölgesi & Nekrotizan fasiit \\
\hline S. intermedius & Köpeklerin derisi & Temas bölgesi & Nekrotizan fasiit \\
\hline $\begin{array}{l}\text { Vibrio türleri } \\
\text { Vibrio vulnificus } \\
\text { Vibrio parahemolyticus } \\
\text { Vibrio cholera }\end{array}$ & $\begin{array}{l}\text { Balıkların deri ve gastroin- } \\
\text { testinal kanalları }\end{array}$ & $\begin{array}{l}\text { Yara veya oral yol ile az pişmiş su } \\
\text { canlıları }\end{array}$ & $\begin{array}{l}\text { Nekrotizan fasit } \\
\text { Ödem } \\
\text { Şişlik } \\
\text { Septisemi* } \\
\text { Ölüm }\end{array}$ \\
\hline Edwardsiella tarda & Balık türleri veya tatlı su & $\begin{array}{l}\text { Açlk yaralar, kesik ve sürtünme } \\
\text { bölgeleri }\end{array}$ & $\begin{array}{l}\text { Nekrotik cilt lezyonları } \\
\text { Gastroenterit } \\
\text { Menenjit } \\
\text { Miyonekroz } \\
\text { Myositis }\end{array}$ \\
\hline $\begin{array}{l}\text { Arcanobacterium haemoly- } \\
\text { ticum }\end{array}$ & Köpek ağız boşluğu, Salya & Isırık bölgesi & Nekrotizan fasiit \\
\hline
\end{tabular}

bir köpek 1sırı̆ğ sonucunda ayak ampütasyonuna kadar ilerleyen Streptococcus agalactiae, Arcanobacterium haemolyticum ve Finegoldia magna etkenlerinin beraberce yaptığı nekrotizan fasiit olgusu tanımlanmıştır (64). Bu etkenlerden A. haemolyticum'un köpekten kaynaklandığ 1 düşünülmüş ve diyabetik bir hastada ilk çoklu mikrobiyal nekrotizan fasiit olgusu olarak literatüre eklenmiştir. İnsanlarda genellikle ampütasyona yol açan yara enfeksiyonlarında Staphylococcus aureus sorumlu tutulmaktadir (65).

\section{SONUÇ}

Sonuç olarak evcil hayvanlardan ve bazı su canlılarından insanlara ssırık ya da deri bütünlüğünün 
bozulması sonucu temas ile bulaşan ve nekrotizan fasiite sebep olan enfeksiyonlar (Tablo 1), insan hayatını ciddi olarak etkilemektedir. Bazı enfeksiyonlarda yalnızca lokal doku ölümü değil septisemi ve çoklu organ yetmezliğine kadar ilerleyebilen bu zoonozlara daha fazla önem verilmelidir. Evcil hayvanların aşılı olmaları durumlarında bile isırık ya da bütünlüğü bozulmuş deri ile temas sonrasinda gerekli hijyen tedbirlerinin alınmasının yanı sıra mutlaka bir hekime başvurulmalıdır. Evcil hayvanların hayatımızda daha fazla yer etmesi ve dostluklarının daha yoğun yaşandığı günümüzde insan hayatını bu denli etkileyen et yiyen zoonozlar daha fazla ciddiye alınmalı, etiyoloji ve klinik yansımaları detaylandırılmalı, hayvanlarla temas halinde olan kișiler konu hakkında bilgilendirilmelidir.

\section{KAYNAKLAR}

1. Köksald1-Motor V, Evirgen Ö, İnci M, Özden R, Doğramac1 AÇ, Gündeşlioğlu AÖ, ve ark. Ciddi bir Yumuşak Doku Enfeksiyonu: Nekrotizan Fasiit (A Serious Soft Tissue Infection: Necrotizing Fasciitis). Tip Araştırmaları Dergisi 2013; 11: 124-127.

2. Hakkarainen TW, Kopari NM, Pham TN, Evans HL. Necrotizing soft tissue infections: review and current concepts in treatment, systems of care, and out comes. Curr Probl Surg 2014; 51: 344-62.

3. Kihiczak GG, Schwartz RA, Kapila R. Necrotizing fasciitis: a deadly infection. J Eur Acad Dermatol Venereol 2006; 20: 365-369.

4. Puvanendran R, Huey JCM, Pasupathy S. Necrotizing fasciitis. Canadian Family Physician 2009; 55: 981-987.

5. Paz Maya S, DualdeBeltrán D, Lemercier P, Leiva-Salinas C. Necrotizing fasciitis: an urgent diagnosis. Skeletal radiology 2014; 43: 577-89.

6. Anaya D, Dellinger E. Necrotizing soft tissue infection: Diagnosis and management. Clin Infect Dis 2007; 44: 705-710.

7. Miller LG, Perdreau-Remington F, Rieg G, Mehdi S, Perlroth J, Bayer AS, et al. Necrotizing fasciitis caused by community associated methicillin resistant Staphylococcus aureus in Los Angeles. N Engl J Med 2005; 352: 1445-1453.

8. Frazee BW, Fee C, Lynn J, Wang R, Bostrom A, Hargis $\mathrm{C}$, et al. Community-acquired necrotizing soft tissue infections: a review of 122 cases presenting to a single emergency department over 12 years. J Emerg Med 2008; 34: 139-146.

9. Gül K. Diyabetes Mellitus Sınıflama, Tanı ve Tarama Testlerine Genel Bakış. KSU Tıp Fak Der. 2015; 10 (2): 12-16.

10. Zazula R, Prucha M, Moravec M, Valeska F. Capnocytophaga canimorsus: Rarecause of Fatal Septic Shock. Case report. Clin Microbiol 2015; 4: 2.

11. Van Dam AP, Van Weert A, Harmanus C, Hovius KE, Claas EC, Reubsaet FA. Molecular characterization of Capnocytophaga canimorsus and other canine Capnocytophaga spp. And assessment by PCR of their frequencies in dogs. J Clin Microbiol 2009: 47; 3218-25.

12. Renzi F, Manfredi P, Dol M, Fu J, Vincent S, Cornelis
GR. Glycan foraging systems reveal the adaptation of Capnocytophaga canimorsus to the dog mouth. mBio 2015; 6(2): e02507-14.

13. Schoen RT, Wohlgelernter D, Barden GE, Swartz TJ. Infectionwith CDC group DF-2 gra -negativerod: report of two cases. Arch Intern Med 1980; 140: 657658.

14. Herbst JS,Raffanti S, Pathy A, Zaiac MN. Dysgonic fermentertype 2 septicemia with purpurafulminans. Dermatologic features of a zoonosis acquired from house hold pets. Arch Dermatol 1989; 125: 13801382.

15. Jordan CS, Miniter U, Yarbrough K, Mengden SJ. Urticarial exanthem associated with Capnocytophaga canimorsus bacteremia after a dog bite. JAAD Case Reports 2016; 2: 98-101.

16. Griego RD, Rosen T, Orengo IF, Wolf JE. Dog, cat, and humanbites: a review. J Am Acad Dermatol 1995; 33: 1019-1029.

17. Lion C, Escande F, Burdin JC. Capnocytophaga canimorsus infections in human: Review of the literature and cases report. Eur J Epidemiol 1996; 12: 523-533.

18. Rossi P, Oger A, Bagneres D, Frances Y, Granel B. Capnocytophaga canimorsus septicaemia in an as plenicpatient with systemic lupus erythematosus. BMJ Case Reports. 2009; 2009:bcr05.2009.1840.

19. Gaastra W, Lipman LJ. Capnocytophaga canimorsus. Vet Microbiol 2010; 140: 339-346.

20. Butler, T. Capnocytophaga canimorsus: an emerging cause of sepsis, meningitis, and post splenectomy infection after dog bites. Eur J Clin Microbiol Infect Dis 2015; 34: 1271-1280.

21. Ota K, Kazawa T, Tsubata C, Suzuki M, Imaoka K. An autory case in volving severe sepsis due to Capnocytophaga canimorsus infection. Kansenshogaku Zasshi 2009; 83: 661-4.

22. Thommen F, Opota O, Greub G, Jaton K, Guex-Crosier Y, Wolfensberger TJ, et al. Capnocytophaga Canimorsus endophthalmitis after cataract surgery linked to salivary dog to human transmission. Retinal Cases and Brief Reports 2017; doi: 10.1097/ ICB.0000000000000637

23. Low SCH, Greenwood JE. Capnocytophaga canimorsus: infection, septicaemia, recovery and reconstruction. J Med Microbiol 2008; 57: 901-903.

24. Shin H, Mally M, Kuhn M, Paroz C, Cornelis GR. Escape from immune Surve illance by Capnocytophaga canimorsus. J Infect Dis 2007; 195: 375-86.

25. Shin H, Mally M, Meyer S, Fiechter C, Paroz C, Zaehringer U. et al. Resistance of Capnocytophaga canimorsus to killing by human complement and polymorphonuclear leukocytes. Infect Immun 2009; 77: 2262-2271.

26. Pers C, Gahrn-Hansen B, Frederiksen W.Capnocytophaga canimorsus septicemia in Denmark, 19821995: review of 39 cases. Clin Infect Dis 1996; 23: 71-75.

27. Hästbacka J, Hynninen M,Kolho E.Capnocytophaga canimorsus bacteremia: clinical features and outco- 
mesfrom a Helsinki ICU cohort. Acta Anaesthesiol Scand 2016; 60: 1437-1443.

28. Kimura R, Hayashi Y, Takeuchi T, Shimizu M, Iwata M, Tanahashi J, et al. Pasteurella multocida septicemia caused by close contact with a domestic cat: case report and literature review. J Infect Chemother 2004; 10: 250-252.

29. Hamamoto Y, Soejima Y, Ogasawara M,Okimura H, Nagai K, Asagami C. Necrotizing fasciitis due to Pasteurella multocida infection. Dermatology 1995; 190: 145-9.

30. Chang K, Siu L K, Chen YH, Lu PL, Chen TC, Hsieh $\mathrm{HC}$, et al. Fatal Pasteurella multocida septicemia and necrotizing fasciitis related with wound licked by a domestic dog. Scand J Infect Dis 2007; 39: 167-70.

31. Erickson ED. Streptococcosis. J Am Vet Med Assoc 1987; 191: 1391-3.

32. Lau SK, Woo PC, Tse H, Leung KW, Wong SS, Yuen KY. Invasive Streptococcus iniaeinfectionsoutside North America. J Clin Microbiol 2003; 41: 1004-9.

33. Lee AS, Dyer JR. Severe Streptococcus zooepidemicus infection in a gardener. Med J Aust 2004; 180: 366.

34. Kittang BR, Pettersen VK, Oppegaard O, Skutlaberg DH, Dale H, Wiker HG. et al. Zoonotic necrotizing myositis caused by Streptococcus equi subsp. zooepidemicus in a farmer. BMC Infect Dis 2017; 17: 147.

35. Lamm CG1, Ferguson AC, Lehenbauer TW, Love BC. Streptococcal infection in dogs: a retrospective study of 393 cases. Vet Pathol. 2010;47: 387-95.

36. Pesavento PA, Bannasch MJ, Bachmann R, Byrne BA, Hurley KF. Fatal Streptococcus canisin fections in intensively housed shelter cats. Vet Pathol 2007; 44: $218-21$.

37. Iglauer F, Kunstyr I, Morstedt R, Farouq H, Wullenweber M, Damsch S. Streptococcus canis arthritis in a cat breeding colony. J Exp Anim Sci 1991; 34: 59-65.

38. DeWinter LM, Low DE, Prescott JF. Virulence of Streptococcus canis from canine streptococcal toxic shock syndrome and necrotizing fasciitis. Vet Microbiol 1999; 70: 95-110.

39. Takeda N, Kikuchi K, Asano R, Harada T, Totsuka K, Sumiyoshi T. et al. Recurrent septicemia caused by Streptococcus canis after a dog bite. Scand J Infect Dis 2001; 33: 927-8.

40. Bert F, Lambert-Zechovsky N. Septicemia caused by Streptococcus canis in a human. J Clin Microbiol 1997; 35: 777-779.

41. Weese S. Flesheating disease from a cat bite. 2012. Erişim adresi: https://www.wormsandgermsblog. com/2012/05/articles/animals/cats/flesh-eating-disease-from-a-cat-bite/ Erişim tarihi: 04.06.2018

42. Ohtaki H, Ohkusu K, Ohta H, Miyazaki T, Yonetamari J, Usui T. et al. A case of sepsis caused by Streptococcus canis in a dog owner: a first cas ereport of sepsis without dog bite in Japan. J Infect Chemother 2013; 19: 1206-1209.

43. Devriese LA, Vancanneyt M, Baele M, Vaneechoutte
M, De Graef E, Snauwaert C, et al. Staphylococcus pseudintermedius sp. nov. a coagulase positive species from animals. Int J Syst Evol Microbiol 2005; 55: 1569-1573.

44. Sasaki T, Kikuchi K, TanakaY, Takahashi N, Kamata S, Hiramatsu K. Methicillin resistant Staphylococcus pseudintermedius in a veterinary teaching hospital. J Clin Microbiol 2007; 45: 1118-1125.

45. Hanselman B, Kruth S, Weese J. Methicillin resistant staphylococcal colonization in dog sentering a veterinary teaching hospital. Vet Microbiol 2008; 126: 277-281.

46. Bannoehr J, Zakour NLB, Waller AS, Guardabassi L, Thoday KL, van den Broek AH. et al. Population genetics tructure of the Staphylococcus intermedius group: insight s into agr diversification and the emergence of methicillin resistant strains. J Bacteriol 2007; 189: 8685-8692.

47. Sasaki T, Kikuchi K, Tanaka Y, Takahashi N, Kamata S, Hiramatsu K. Reclassification of phenotypically identified Staphylococcus intermedius strains. J Clin Microbiol 2007; 45: 2770-2778.

48. Morris D, Rook K, Shofer F, Rankin S. Screening of Staphylococcus aureus, Staphylococcus intermedius, and Staphylococcus schleiferi isolatesobtained from small companion animals foranti microbial resistance: A retrospective review of 749 isolates (20032004). Vet Dermatol 2006; 17: 332-337.

49. Weese JS, Poma R, James F, Buenviaje G, Foster R, Slavic D. Staphylococcus pseudintermedius necrotizing fasciitis in a dog. Can Vet J 2009; 50: 655-6.

50. Imamura Y, Kudo Y, Ishii Y, Shibuya H,Takayasu S. A case of subacute necrotizing fasciitis. J Dermatol 1995; 22: 960-963.

51. Eastaugh J, Shepard S. Infectious and toxic syndromes for fish and shell fish consumption: a review. Arch Intern Med 1989; 149: 1735-1740.

52. Bisharat N, Agmon V, Finkelstein R, Raz R, Ben-Dror $G$, Lerner L, et al. Clinical, epidemiological, and microbiological features of Vibrio vulnificus bio group 3 causing out breaks of wound infection and bacteraemia in Israel. The Lancet 1999; 354: 1421-1424.

53. Lehane L, Rawlin GT. Topically acquired bacterial zoonoses from fish: a review. Med J Aust 2000; 173: 256-259.

54. Tang WM, Fung KK, Cheng VC, Lucke L. Rapidly progressive necrotising fasciitis following a Stone fishsting: a report of two cases. J Orthop Surg 2006; 14: 67-70.

55. Oliver JD. Wound infections caused by Vibrio vulnificus and other marine bacteria. Epidemiol Infect 2005; 133: 383-391.

56. American College of Physicians web site. MKSAP Quiz: Fever, chills, rash in the ED. https://acpinternist.org/archives/2013/05/mksap.htm Erişim tarihi: 31.05.2018

57. Nemetz T, Shotts E. Zoonotic diseases. 214-220. In: Stoskopf M (Ed), Fish medicine. 1993: WB Saunders Co., Philadelphia. 
58. Hawke JP, Durborow RM, Thune RL, Camus AC. ESC: enteric septicemia of catfish. Stoneville, Mississippi: SouthernRegionalAquaculture Center 1998; 477: $1-6$.

59. Jordon GW, Hadley WK. Human infection with Edwardsiella tarda. Ann Int Med 1969; 70: 283-288.

60. Vandepitte J, Lemmens P, de Swert L. Human edwardsiellosis traced to ornamental fish. J Clin Microbiol 1983; 17: 165-167.

61. Matsushima S, Yajima S, Taguchi T, Takahashi A, Shiseki M, Totsuka K, et al. A fulminating case of Edwardsiella tarda septicemia with necrotizing fasciitis. Kansenshogakuzasshi 1996; 70: 631-636.

62. Wilson JP, Waterer RR, Wofford JD, Chapman SW. Serious infections with Edwardsiella tarda: a case report and review of the literature. Arch Intern Med
1989; 149: 208-210.

63. Slaven EM, Lopez FA, Hart SM, Sanders CV. Myonecrosis caused by Edwardsiella tarda: a case report and case series of extra intestinal E. tarda infections. Clin Infect Dis 2001; 32: 1430-1433.

64. Lee S, Roh KH, Kim CK, Yong D, Choi JY, Lee JW, et al. A case of necrotizing fasciitis due to Streptococcus agalactiae, Arcanobacterium haemolyticum, and Finegoldia magna in a dog bitten patient with diabetes. Korean J Lab Med 2008; 28(3): 191-5.

65. Lipsky BA, Berendt AR, Deery HG, et al. Diagnosis and treatment of diabetic foot infections. Plast Reconstr Surg 2006; 117: 212S-238S. 